\title{
Amelioration of an LPS-induced inflammatory response using a methanolic extract of Lagerstroemia ovalifolia to suppress the activation of NF-kB in RAW264.7 macrophages
}

\author{
JI-WON PARK ${ }^{1,2}$, OK-KYOUNG KWON ${ }^{1,3}$, PRASETYAWAN YUNIATO ${ }^{4}$, \\ BAMBANG MARWOTO ${ }^{4}$, JOONGKU LEE ${ }^{5}$, SEI-RYANG OH ${ }^{1}$, \\ $\mathrm{JAE}-H O N G ~ K I M^{2}$ and KYUNG-SEOP AHN ${ }^{1}$
}

\begin{abstract}
${ }^{1}$ Natural Medicine Research Center, Korea Research Institute of Bioscience and Biotechnology (KRIBB), Cheongju-si, Chungbuk 363-883; ${ }^{2}$ College of Life Sciences and Biotechnology, Korea University, Seoul 136-701;

${ }^{3}$ Department of Toxicology, College of Pharmacy, Chungnam National University, Daejeon 305-764, Republic of Korea; ${ }^{4}$ Center for Pharmaceutical and Medical Technology, The Agency for the Assessment and Application of Technology (BPPT), Tangerang, Banten 15314, Indonesia; ${ }^{5}$ Department of Environment and Forest Resources, Chungnam National University, Yuseong-gu, Daejeon 34134, Republic of Korea
\end{abstract}

Received May 19, 2015; Accepted June 2, 2016

DOI: $10.3892 /$ ijmm.2016.2646

\begin{abstract}
Lagerstroemia ovalifolia Teijsm. \& Binn. has traditionally been used as an herbal medicine and possesses anti-inflammatory properties. However, the mechanisms underlying its anti-inflammatory effects remain poorly understood. For this purpose, we aimed to investigate the effects of methanolic extract of L. ovalifolia (LOME) on nitric oxide (NO) and prostaglandin $\mathrm{E}_{2}\left(\mathrm{PGE}_{2}\right)$ production, as well as the underlying molecular mechanisms responsible for these effects, in lipopolysaccharide (LPS)-stimulated RAW264.7 macrophages. We examined the effects of LOME on the production of NO and $\mathrm{PGE}_{2}$ in LPS-stimulated RAW264.7 cells. To explore the anti-inflammatory mechanisms of LOME, we measured the mRNA or protein expression of the pro-inflammatory mediators induced by LOME in the LPS-stimulated RAW264.7 cells. LOME significantly inhibited the production of $\mathrm{NO}, \mathrm{PGE}_{2}$, interleukin (IL)-6, IL-1 $\beta$, and tumor necrosis factor- $\alpha$ (TNF- $\alpha$ ) in LPS-stimulated RAW264.7 cells. Moreover, LOME suppressed the mRNA and protein expression of inducible nitric oxide synthase (iNOS), cyclooxygenase-2 (COX-2) and inhibited the phosphorylation of the mitogen-activated protein kinases (MAPKs), with a reduction in the nuclear transloca-
\end{abstract}

Correspondence to: Dr Kyung-Seop Ahn, Natural Medicine Research Center, Korea Research Institute of Bioscience and Biotechnology, 30 Yeongudanji-ro, Ochang-eup, Cheongwon-gu, Cheongju-si, Chungbuk 363-883, Republic of Korea

E-mail: ksahn@kribb.re.kr

Key words: Lagerstroemia ovalifolia Teijsm. \& Binn, inflammation, lipopolysaccharide, MARK, NF- $\mathrm{B}$ tion of nuclear factor (NF)- $\kappa$ B in LPS-stimulated RAW264.7 cells. Taken together, these findings suggest that LOME may exert anti-inflammatory effects in vitro in LPS-stimulated RAW264.7 macrophages and thus, may have potential for use as an adjuvant treatment of inflammatory diseases.

\section{Introduction}

Inflammation is one of most important and ubiquitous defensive reactions to stimuli, such as toxins and pathogens, and it is characterized by redness, pain, swelling, and a sensation of heat at the site of infection (1). During the inflammatory process, a number of inflammatory cells infiltrate the damaged tissue and produce inflammatory mediators that exaggerate inflammatory responses. Nitric oxide (NO), prostaglandin $(\mathrm{PG}) \mathrm{E}_{2}$, interleukins (ILs) and tumor necrosis factor- $\alpha$ (TNF- $\alpha)$, produced by the infiltrated cells or damaged tissue, act as pleiotropic effector molecules to amplify acute inflammation and lead to the activation of adaptive immune responses $(2,3)$. Thus, it is essential that the inflammatory process be controlled spatiotemporally to prevent unwanted tissue damage and the development of inflammation-associated disorders.

Macrophages play a central role in inflammatory diseases and produce many pro-inflammatory cytokines, such as IL-6, TNF- $\alpha$ and IL-1 $\beta$. Macrophages also produce inflammatory mediators, including $\mathrm{NO}$ and $\mathrm{PGE}_{2}$ (4). As the major component of the outer membrane of Gram-negative bacteria cell walls, lipopolysaccharide (LPS) is capable of stimulating macrophages to produce pro-inflammatory cytokines, including TNF- $\alpha$ and IL-6, and inflammatory mediators such as $\mathrm{NO}$ and $\mathrm{PGE}_{2}$ (5). $\mathrm{NO}$ is produced by inducible nitric oxide synthase (iNOS) and mediates many disease processes including atherosclerosis, inflammation, carcinogenesis, hypertension, obesity and 
diabetes (6-8). $\mathrm{PGE}_{2}$ is a major cyclooxygenase $(\mathrm{COX})$ product at inflammatory sites, where it contributes to local increases in blood flow, edema formation and pain sensitization (9). Thus, the inhibition of these pro-inflammatory mediators may be an effective strategy for the treatment of inflammatory diseases.

Lagerstroemia ovalifolia Teijsm. \& Binn. (LO) is a member of the Lythraceae family $(10,11)$. This tree species has commercial value. It is used for medium-heavy construction (door, window frames), bridge and boat building, various agriculture implements and tool handles. LO has traditionally been used as an herbal medicine in Java without distinction of related species (e.g., L. speciosa) without distinction of species; the bark for diarrhea, the leaves for malaria and dermatosis $(12,13)$. The effects and biological activity of the methanolic extract of LO (LOME) on inflammation, as well as the mechanisms of action responsible for these effects remain largely unknown. To date, this plant has shown few and unclear effects to the best of our knowledge. In the present study, we examined the anti-inflammatory effects of LOME in various experiments. We used an LPS-stimulated, murine macrophage cell line, RAW264.7, as a model of inflammation to determine the effects of LOME. The binding of LPS to downstream signaling cascades, including mitogen-activated protein kinases (MAPKs) and nuclear factor- $\kappa \mathrm{B}(\mathrm{NF}-\kappa \mathrm{B})$ pathways (14), led to the production of inflammatory mediators from macrophages, such as TNF- $\alpha$, IL- $1 \beta$, IL-6, PGE 2 and NO. Our results indicated that LOME inhibited $\mathrm{NO}, \mathrm{PGE}_{2}$ and the pro-inflammatory cytokines in LPS-stimulated macrophages through NF- $\kappa \mathrm{B}$ signaling, as well as the MAPK, extracellular signal-regulated kinase (ERK)1/2, p38 and c-Jun N-terminal kinase (JNK) $1 / 2$ pathways. These results provide evidence for the use of LOME as an anti-inflammatory treatment.

\section{Materials and methods}

Materials. LO was collected from the Ujung Kulon National Park, in the province of Banten, Indonesia. Plant samples were collected and identified by staff at the Center for Pharmaceutical and Medical Technology (PTFM; Tangerang, Indonesia), and verified at the Herbarium Bogoriense (LIPI; Bogor, Indonesia). Voucher specimens recorded as KRIB 0038535 and PMT 537, have been deposited in the herbarium (KRIB) of the Korea Research Institute of Bioscience and Biotechnology (Daejeon, Korea) as well as in the Center for Pharmaceutical and Medical Technology (PTFM) and the Herbarium Bogoriense. After drying and grinding the leaves of LO, the powder $(10.8 \mathrm{~kg})$ was added to methanol (100 liters). The extraction was performed using the method of repercolation at room temperature. The extract was filtered and concentrated by a rotary evaporator (Rotavapor 4000; Heidolph, PT AbadiNusa Usahasemesta, Jakarta) under reduced pressure, to obtain 1,030 g LOME. In subsequent experiments, LOME was dissolved in dimethyl sulfoxide (DMSO) at a concentration of $20 \mathrm{mg} / \mathrm{ml}$, and then diluted to various concentrations prior to use.

Cell culture. The murine macrophage cell line RAW264.7 was obtained from the American Type Culture Collection (ATCC; Rockville, MD, USA). The cells were grown in Dulbecco's modified Eagle's medium (DMEM; Gibco-BRL, Grand Island, NY, USA) supplemented with $10 \%$ heat-inac- tivated fetal bovine serum (FBS; HyClone, Logan, UT, USA) and $1 \%$ antibiotic-antimycotic solution (Invitrogen, Grand Island, NY, USA). The RAW264.7 cells were maintained by weekly passage, and the cells were utilized for experimentation at $60-80 \%$ confluence. Following the incubation of the RAW264.7 cells for $4 \mathrm{~h}, 0-30 \mu \mathrm{g} / \mathrm{ml}$ LOME was added.

Determination of cell viability. Cell viability was determined by the mitochondrial-dependent reduction of 3-(4,5-dimethylthiazol-2-yl)-2,5-diphenyltetrazolium bromide (MTT; Amresco, LLC, Solon, OH, USA) to purple formazan. Briefly, the RAW264.7 cells were seeded into each well of 96-well plates at a density of $1 \times 10^{4}$ cells/well. After $4 \mathrm{~h}$, the cells were treated with LOME for $24 \mathrm{~h}$. MTT solution $(5 \mu \mathrm{l} ; 5 \mathrm{mg} / \mathrm{ml})$ was then added to each well. After a $4 \mathrm{~h}$ incubation at $37^{\circ} \mathrm{C}$ with $5 \% \mathrm{CO}_{2}$, the supernatant was removed and the formazan crystals formed by the viable cells were dissolved in $100 \mu \mathrm{l}$ DMSO. The absorbance of each well was read at $570 \mathrm{~nm}$ using a microplate reader (Benchmark; Bio-Rad Laboratories, Inc., Hercules, CA, USA). Based on the results of the cytotoxicity assay, we used a nontoxic concentration of LOME on the RAW264.7 cells in subsequent experiments.

NO assay. Nitrite concentration in the medium was measured as an indicator of NO production according to the Griess reaction method, as previously described (15). The RAW264.7 cells were plated at a density of $2.5 \times 10^{5}$ cells $/ \mathrm{ml}$ in 96 -well plates, and then incubated with or without LPS $(0.5 \mu \mathrm{g} / \mathrm{ml})$ in the absence or presence of various concentrations of LOME for $24 \mathrm{~h}$. The nitrite accumulation in the supernatant was assessed by a Griess reaction. Each $100 \mu \mathrm{l}$ of the culture supernatant was mixed with an equal volume of the Griess reagent [0.1\% N-(1-naphthyl)ethylenediamine and $1 \%$ sulfanilamide in $5 \%$ phosphoric acid] and incubated at room temperature for $10 \mathrm{~min}$. The absorbance was measured at $540 \mathrm{~nm}$ using a microplate reader (Benchmark; Bio-Rad Laboratories, Inc.) and a series of known concentrations of sodium nitrite were used as a standard.

$P G E_{2}$ assay. The RAW264.7 cells were plated at a density of $2.5 \times 10^{5}$ cells $/ \mathrm{ml}$ in a 96 -well culture plate. The cells were incubated with various concentrations $(5,10,20$ or $30 \mu \mathrm{g} / \mathrm{ml})$ of LOME for $1 \mathrm{~h}$, followed by LPS treatment $(0.5 \mu \mathrm{g} / \mathrm{ml})$ for $24 \mathrm{~h}$. Following a $24 \mathrm{~h}$ incubation, the $\mathrm{PGE}_{2}$ concentration in the culture media was quantified using an enzyme-linked immunosorbent assay (ELISA) kit (Cayman Chemical Co., Ann Arbor, MI, USA) according to manufacturer's instructions.

Cytokine assays. The levels of IL-6, IL-1 $\beta$ and TNF- $\alpha$ were determined using commercial ELISA kits. IL-6, IL-1 $\beta$ and TNF- $\alpha$ were purchased from R\&D Systems, Inc. (Minneapolis, MN, USA). The assay procedure for each kit was conducted according to the manufacturer's instructions. The concentrations of the mediators were determined at $450 \mathrm{~nm}$ using a microplate reader (Benchmark; Bio-Rad Laboratories, Inc.).

Semi-quantitative reverse transcription $(R T)$ - $P C R$. RT-PCR was performed to detect the mRNA expression of iNOS, COX-2, IL-6, IL-1 $\beta$, TNF- $\alpha$ and $\beta$-actin. Briefly, after LPS $(0.5 \mu \mathrm{g} /$ ml) stimulation of the RAW264.7 cells for $6 \mathrm{~h}$, total RNA was isolated using TRIzol ${ }^{\mathrm{TM}}$ reagent (Invitrogen, Carlsbad, 
CA, USA) according to the manufacturer's instructions. An RT reaction was perormed using a kit for producing cDNA (Qiagen GmbH, Hilden, Germany). PCR was performed using specific forward and reverse primers, and a premix according to the manufacturer's instructions (Bioneer Corporation, Daejeon, Korea). The PCR conditions for each PCR reaction were as follows: $94^{\circ} \mathrm{C}$ for $5 \mathrm{~min}(1 \mathrm{cycle}), 94^{\circ} \mathrm{C}$ for $30 \mathrm{sec}, 60^{\circ} \mathrm{C}$ for $30 \mathrm{sec}$, and $72^{\circ} \mathrm{C}$ for $45 \mathrm{sec}$ (for 30 cycles); and then a final extension phase at $72^{\circ} \mathrm{C}$ for $10 \mathrm{~min}$. The primer sequences were as follows: TNF- $\alpha$ sense, $5^{\prime}$-CAT CTT CTC AAA ATT CGA GTG ACA A-3' and antisense, 5'-TGG GAG TAG ACA AGG TAC AAC CC-3'; IL-1 $\beta$ sense, 5'-GTG TCT TTC CCG TGG ACC TT-3' and antisense; 5'-TCG TTG CTT GGT TCT CCT TG-3'; IL-6 sense, 5'-AAC GAT GAT GCA CTT GCA GA-3' and antisense, 5'-GAG CAT TGG AAA TTG GGG TA-3'; iNOS sense, 5'-CAA GAG TTT GAC CAG AGG ACC-3' and antisense, 5'-TGG AAC CAC TCG TAC TTG GGA-3'; COX-2 sense, 5'-GAA GTC TTT GGT CTG GTG CCT G-3' and antisense, 5'-GTC TGC TGG TTT GGA ATA GTT GC-3'; and $\beta$-actin sense, 5'-TGT TTG AGA CCT TCA ACA CC-3' and antisense, 5'-CGC TCA TTG CCG ATA GTG AT-3'. $\beta$-actin expression was included as an internal, housekeeping gene control. The reaction products were separated by electrophoresis on a $1.5 \%$ agarose gel, stained with $\mathrm{EtBr}$, and visualized by UV transillumination (CoreBioSystem, Seoul, Korea). The images were captured using an Olympus $\mathrm{C} 4000$ zoom camera system (C4000; Olympus America Inc., Melville, NY, USA).

Western blot analysis. The RAW264.7 macrophages were pretreated with the indicated concentrations of LOME or vehicle for $1 \mathrm{~h}$ and stimulated with LPS $(0.5 \mu \mathrm{g} / \mathrm{ml})$ for $20 \mathrm{~min}$ (phosphor) and $18 \mathrm{~h}$ (COX-2 and iNOS). Proteins in each sample (30 $\mu \mathrm{g}$ of total protein) were resolved on a 10\% sodium dodecyl sulfate (SDS)-polyacrylamide gel by SDS-polyacrylamide gel electrophoresis (PAGE). The proteins were transferred to a polyvinylidene difluoride (PVDF) membrane and exposed to the appropriate antibodies. Each membrane was incubated for $1 \mathrm{~h}$ in 5\% skim milk in TBS-T buffer $(0.1 \mathrm{M}$ Tris-HCl, $\mathrm{pH} 7.4$, $0.9 \% \mathrm{NaCl}$ and $0.1 \%$ Tween-20) to block non-specific binding, and then incubated with primary antibodies that recognized p65 (cat. no. sc-372, 1:1,000; Santa Cruz Biotechnology, Inc., Santa Cruz, CA, USA); iкB $\alpha$ (cat. no. 9242, 1:1,000; Cell Signaling Technology, Inc., Danvers, MA, USA), iNOS (cat. no. ADI-905-431, 1:1,000; obtained from Enzo Life Sciences, Inc., Farmingdale, NY, USA); COX-2 (cat. no. sc-1747, 1:1,000; Santa Cruz Biotechnology, Inc.); $\beta$-actin (cat. no. 4967, 1:2,000) and PARP (cat. no. 9542) (both from Cell Signaling Technology, Inc.); the total forms of ERK2 (sc-154), p38 MAPK (sc-7149), JNK1/3 (sc-474) (1:1,000, all from Santa Cruz Biotechnology, Inc.); the phosphorylated forms of p38 MAPK (ADI-KAP-MA022) and JNK1/2 (KAPSA011 (1:1,000; both from Enzo Life Sciences, Inc.); and the phosphorylated forms of ERK (9106, 1:1,000; Cell Signaling Technology, Inc.). Each protein was detected using an enhanced chemiluminescence (ECL) detection system (Bio-Rad Laboratories, Inc.).according to manufacturer's instructions

Immunocytochemistry. The RAW264.7 cells were cultured on Permanox plastic chamber slides (Nalge Nunc International, Rochester, NY, USA) and fixed in methanol at $4^{\circ} \mathrm{C}$ for $20 \mathrm{~min}$.

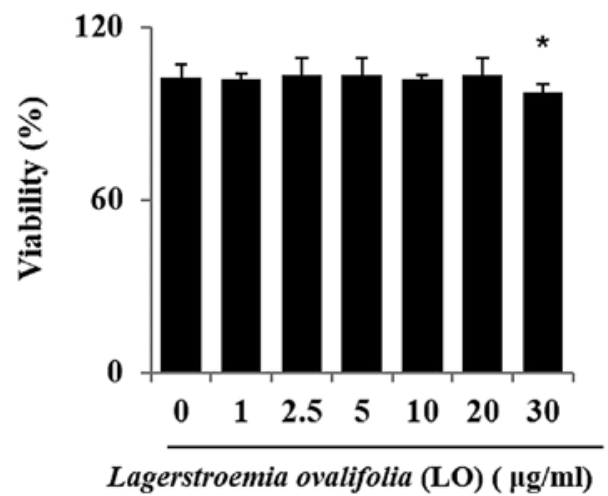

Figure 1. Effect of methanolic extract of L.ovalifolia (LOME) on cell viability. RAW264.7 cells were incubated in the presence or absence of $0-30 \mu \mathrm{g} / \mathrm{ml}$ LOME, and the cell viability was determined using an MTT assay. The data are the means \pm SEM of three independent experiments. ${ }^{*} \mathrm{P}<0.05$.

The slides were washed three times with phosphate-buffered saline (PBS) and blocked with $3 \%(\mathrm{w} / \mathrm{v}) \mathrm{BSA}$ in PBS for a further $30 \mathrm{~min}$. The slides were then incubated for $24 \mathrm{~h}$ at $4^{\circ} \mathrm{C}$ with anti-iNOS (rabbit polyclonal IgG, 1:200 dilution), and anti-NF-kB p65 subunit (rabbit polyclonal IgG, 1:200 dilution) (both from Santa Cruz Biotechnology, Inc.) antibodies. After washing to remove excess primary antibody, the slides were further incubated with anti-rabbit Alexa Fluor 488-conjugated antibody (Invitrogen, Carlsbad, CA, USA) for $2 \mathrm{~h}$ at room temperature, washed with PBS, and mounted using ProLong Gold Antifade reagent containing 4',6-diamidino-2-phenylindole (DAPI; Invitrogen, Carlsbad, CA, USA) for $5 \mathrm{~min}$, prior to the localization and quantification of the nuclei. Subsequently, the slides were cover-slipped and visualized using a confocal laser scanning microscope (LSM510m; Carl Zeiss, Inc., Oberkochen, Germany). Images of the samples were captured under the same exposure conditions, and the nuclei were quantified from the images obtained.

Statistical analysis. For the statistical analyses, the values are expressed as the means \pm SEM of the sample determinations. The statistical significance was determined using a two-tailed Student's t-test for independent means, and a P-value $<0.05$ was considered to indicate a statistically significant difference.

\section{Results}

Evaluation of the cytotoxicity of LOME in RAW264.7 cells. A prerequisite to studying the biological activity of LOME was to ensure that it did not exert a detrimental effect on cell metabolism. To determine whether LOME affected cell viability, the RAW264.7 cells were incubated for $24 \mathrm{~h}$ with the extract at a wide range of concentrations $(0-30 \mu \mathrm{g} / \mathrm{ml})$, and cell viability was evaluated using an MTT assay. A statistically significant decrease in cell survival was observed at a concentration of $30 \mu \mathrm{g} / \mathrm{ml}$ (Fig. 1).

LOME reduces the production of NO by suppressing iNOS expression in LPS-stimulated RAW264.7 cells. As it is important to regulate the overproduction of $\mathrm{NO}$, which induces pro-inflammatory responses in inflammatory disorders (16), we examined the effect of LOME on the regulation of 


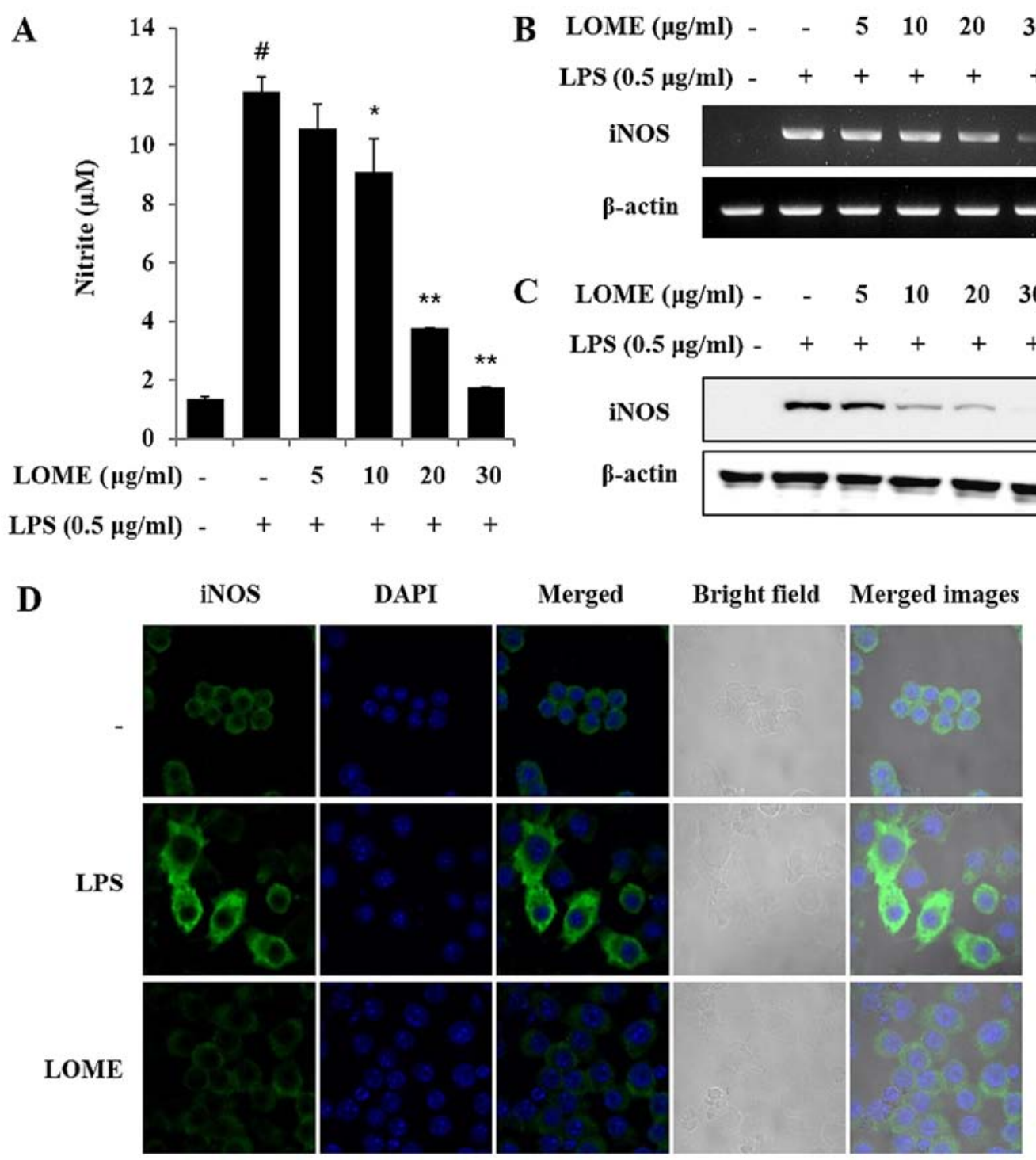

Figure 2. Methanolic extract of L. ovalifolia (LOME) inhibits lipopolysaccharide (LPS)-induced nitric oxide (NO) production and inducible nitric oxide synthase (iNOS) expression in RAW264.7 cells. (A) RAW264.7 cells were treated with the LOME $(5,10,20 \mathrm{or} 30 \mu \mathrm{g} / \mathrm{ml})$ for $1 \mathrm{~h}$ and then stimulated with LPS $(0.5 \mu \mathrm{g} / \mathrm{ml})$. The culture media were collected at $24 \mathrm{~h}$, and the NO concentrations were measured using the Griess reaction. Three independent experiments were performed, and the data are presented as the means \pm SEM. ${ }^{*} \mathrm{P}<0.05$ and ${ }^{* *} \mathrm{P}<0.01$, compared with the cells treated with LPS alone. The hash symbol (\#) is used to indicate the negative control, error range. (B) RAW264.7 cells were treated with LOME for $1 \mathrm{~h}$ and stimulated with LPS for $6 \mathrm{~h}$. $\beta$-actin expression was used as an internal control for RT-PCR. (C) RAW264.7 cells were treated with LOME for $1 \mathrm{~h}$ and stimulated with LPS for $18 \mathrm{~h}$. Cell lysates were obtained, the iNOS protein levels were evaluated using western blot analysis, and $\beta$-actin expression was used as an internal control. (D) The cells were treated with LOME for $1 \mathrm{~h}$ and stimulated with LPS for a further $20 \mathrm{~h}$. Cellular localization of iNOS was determined by immunocytochemistry. Following fixation, the cells were stained with blue and green labels (magnification, $\mathrm{x} 400)$. Control, DMSO (0.1\%); LPS, LPS only ( $0.5 \mu \mathrm{g} / \mathrm{ml}) ; \mathrm{LOME}, \mathrm{LOME}(30 \mu \mathrm{g} / \mathrm{ml})$ and LPS.

NO production in LPS-stimulated macrophages. Prior to evaluating the regulatory effect of LOME in LPS-stimulated macrophages, we first confirmed that LOME did not induce NO production in the RAW264.7 cells. However, the pre-incubation of cells with LOME for $1 \mathrm{~h}$ prior to LPS stimulation resulted in reduced NO production compared with that in the LPS-stimulated RAW264.7 cells. Furthermore, NO production was gradually attenuated by increasing the concentration of LOME up to $30 \mu \mathrm{g} / \mathrm{ml}$ (Fig. 2A). To determine whether LOME reduces $\mathrm{NO}$ production by regulating protein expression, we measured the expression of iNOS in the RAW264.7 cells by RT-PCR and western blot analysis. According to this analysis, iNOS expression was downregulated in a dose-dependent manner (Fig. 2C and D). We further examined the effect of
LOME, which inhibits iNOS, using immunocytochemistry. The iNOS levels were markedly increased in LPS-stimulated cells (Fig. 2D); however, pre-incubation with the LOME prevented the expression of these proteins. Thus, we suggest that LOME inhibits iNOS production.

$L O M E$ decreases the production of $P G E_{2}$ by suppressing $C O X-2$ expression in LPS-stimulated RAW264.7 cells. The unstimulated RAW264.7 cells secreted basal levels of $\mathrm{PGE}_{2}$ and LPS stimulation induced an increase in $\mathrm{PGE}_{2}$ production (Fig. $3 \mathrm{~A}$ ). In a dose-response study, LOME treatment significantly diminished LPS induction of COX-2, which corresponded with a decreased accumulation of $\mathrm{PGE}_{2}$ in the culture media (Fig. 3). The LPS-stimulated RAW264.7 cells overexpressed COX-2 
A

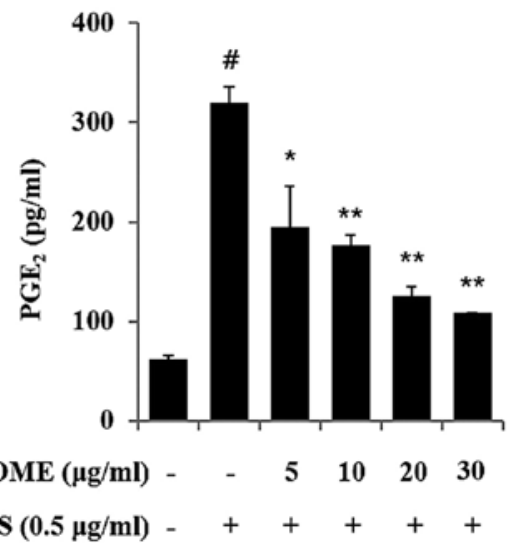

B LOME $(\mu \mathrm{g} / \mathrm{ml})-\quad-\quad \begin{array}{llll}5 & 10 & 20 & 30\end{array}$

LPS $(0.5 \mu \mathrm{g} / \mathrm{ml})-++++$

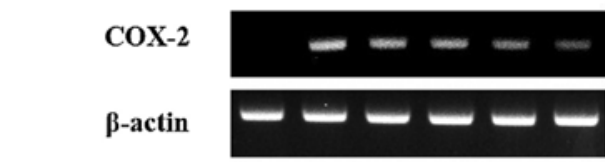

C LOME $(\mu \mathrm{g} / \mathrm{ml})-\quad-\quad \begin{array}{rrrr}5 & 10 & 20 & 30\end{array}$

LPS $(0.5 \mu \mathrm{g} / \mathrm{ml})-++++$

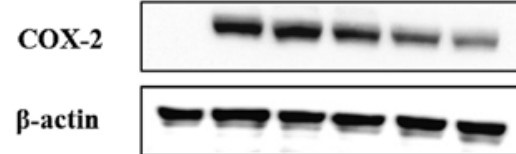

Figure 3. Methanolic extract of L. ovalifolia (LOME) inhibits lipopolysaccharide (LPS)-induced prostaglandin $\mathrm{E}_{2}\left(\mathrm{PGE}_{2}\right)$ production and cyclooxygenase (COX)-2 expression in RAW264.7 cells. (A) RAW264.7 cells were treated with $\operatorname{LOME~}(5,10,20$ or $30 \mu \mathrm{g} / \mathrm{ml})$ for $1 \mathrm{~h}$ and then stimulated with LPS (0.5 $\mu \mathrm{g} / \mathrm{ml})$. The culture media were collected at $24 \mathrm{~h}$, and the $\mathrm{PGE}_{2}$ concentrations were measured using an enzyme-linked immunosorbent assay. Three independent experiments were performed, and the data are presented as the means \pm SEM. ${ }^{~} \mathrm{P}<0.05$ and ${ }^{* *} \mathrm{P}<0.01$, compared with the cells treated with LPS alone. The hash symbol (\#) is used to indicate the negative control, error range. (B) RAW264.7 cells were treated with LOME for $1 \mathrm{~h}$ and stimulated with LPS for $6 \mathrm{~h}$. $\beta$-actin expression was used as an internal control for RT-PCR. (C) RAW264.7 cells were treated with LOME for $1 \mathrm{~h}$ and stimulated with LPS for $24 \mathrm{~h}$. $\beta$-actin expression was used as an internal control for western blot analysis.

A

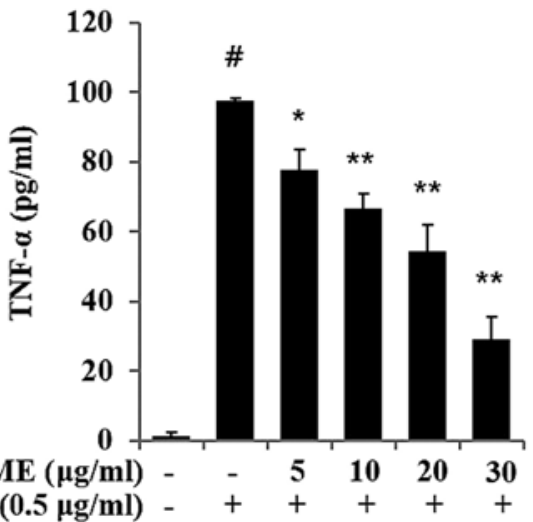

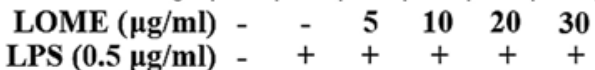

C

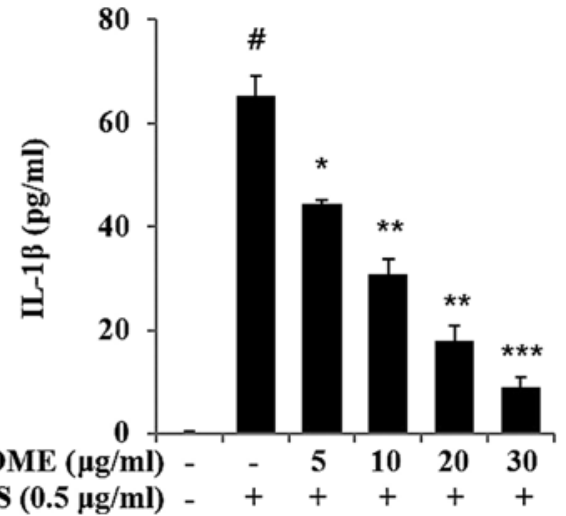

B

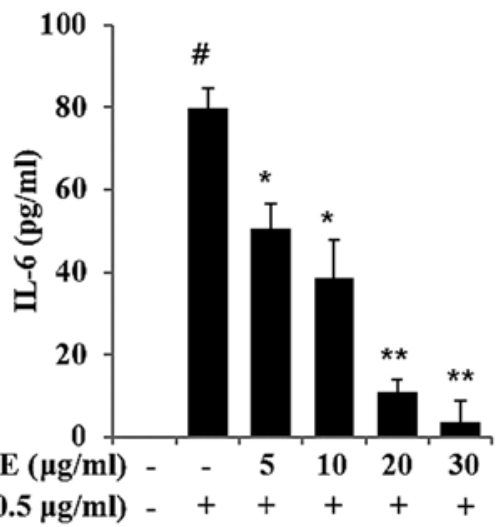

D

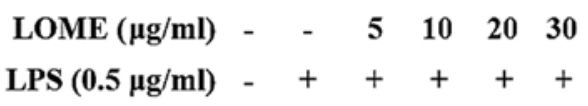

TNF- $\alpha$

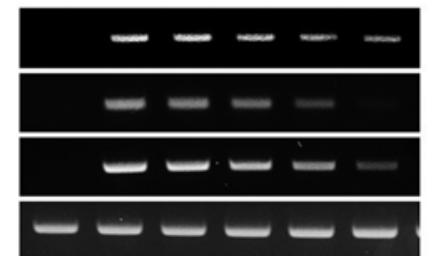

Figure 4. Methanolic extract of L. ovalifolia (LOME) inhibits interleukin (IL)-6, IL-1 $\beta$ and TNF- $\alpha$ production in lipopolysaccharide (LPS)-stimulated RAW264.7 cells. Effects of LOME on (A) tumor necrosis factor- $\alpha$ (TNF- $\alpha$ ), (B) IL-6 and (C) IL-1 $\beta$ production in LPS-stimulated RAW264.7 macrophages. RAW264.7 cells were treated with various concentrations of $\operatorname{LOME}(5,10,20$ and $30 \mu \mathrm{g} / \mathrm{ml})$ for $1 \mathrm{~h}$ prior to the addition of LPS $(0.5 \mu \mathrm{g} / \mathrm{ml})$, and the cells were further incubated for $18 \mathrm{~h}$. The culture supernatant was subjected to an enzyme-linked immunosorbent assay (ELISA). (D) RAW264.7 cells were treated with LOME for $1 \mathrm{~h}$ and stimulated with LPS for $6 \mathrm{~h}$. The total RNA was isolated, and the mRNA levels encoding IL-6, IL-1 $\beta$ and TNF- $\alpha$ were evaluated using RT-PCR. The data are presented as the means \pm SEM of three samples. Statistically significant differences ( $\mathrm{P}<0.05$ and ${ }^{* * *} \mathrm{P}<0.01$; the hash symbol (\#) is used to indicate the negative control, error range) compared with the cells treated with LPS alone.

mRNA, whereas the LOME-treated RAW264.7 cells stimulated with LPS, exhibited decreased expression of COX-2 mRNA. COX-2 protein expression was consistent with the mRNA results (Fig. 3B and C). LOME inhibited COX-2 protein expression in the RAW264.7 cells stimulated with LPS.
$L O M E$ reduces the release of pro-inflammatory cytokines in LPS-stimulated RAW264.7 cells. The levels of TNF- $\alpha$, IL-1 $\beta$ and IL- 6 were measured in the media of RAW264.7 cells that were treated with varying concentrations of LOME, and then treated with $0.5 \mu \mathrm{g} / \mathrm{ml}$ of LPS (Fig. 4A-C). It was found 


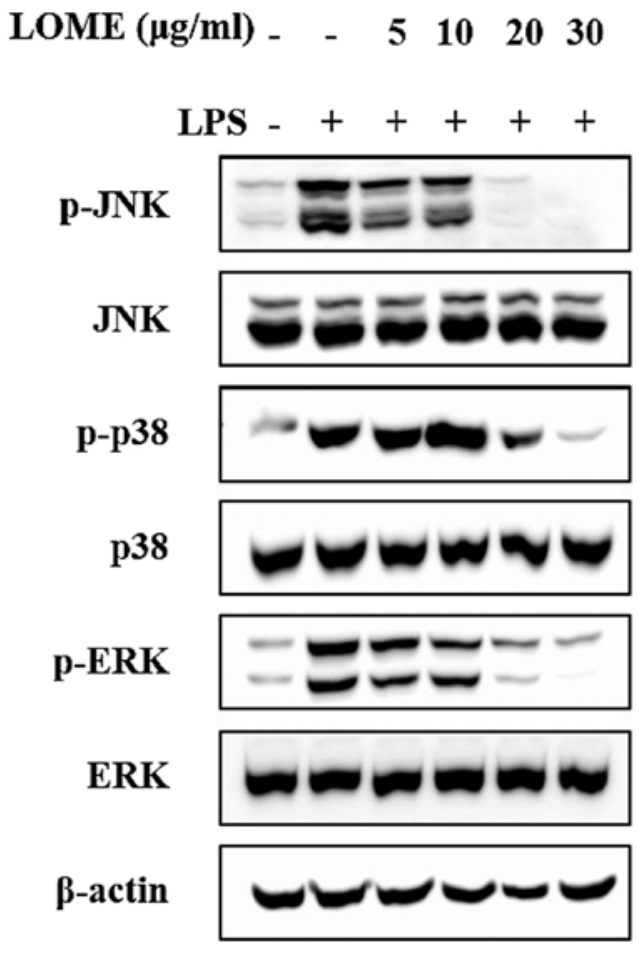

Figure 5. Methanolic extract of L. ovalifolia (LOME) suppresses the phosphorylation of mitogen-activated protein kinase (MAPK) molecules in lipopolysaccharide (LPS)-stimulated RAW264.7 cells. The effect of LOME on the activity of signaling enzymes upstream from MAPK translocation. Levels of phosphorylated and total ERK, JNK and p38 proteins (upstream activators of nuclear factor (NF)- $\kappa \mathrm{B}$ translocation) were determined in RAW264.7 cells using antibodies to the phosphorylated and total proteins. The representative results of three independent experiments are shown.

that LOME significantly reduced the production of TNF- $\alpha$, IL-1 $\beta$ and IL-6 in a dose-dependent manner (Fig. 4A-C). LOME alone had no effect on TNF- $\alpha$, IL- $1 \beta$ and IL- 6 production in the RAW264.7 cells (data not shown). Additionally, the mRNA levels of TNF- $\alpha$, IL- $1 \beta$ and IL- 6 were evaluated using RT-PCR (Fig. 4D). Changes in the mRNA expression of TNF- $\alpha$, IL- $1 \beta$ and IL- 6 were similar to those observed in their protein expression levels.

Effects of LOME on the activation of MAPKs in LPS-stimulated RAW264.7 cells. Three MAPKs, namely ERK, p38 and JNK, are known to be activated by LPS. MAPKs play an important role in the transcriptional regulation of the LPS-induced expression of iNOS and COX-2 by activating the transcription factor NF- $\kappa B$ (17). As shown in Fig. 5, LOME clearly decreased the phosphorylation of ERK1/2, JNK and p38. These results indicate that the inhibitory effect of LOME on TNF- $\alpha$, IL- $1 \beta$, IL-6, NO and PGE $_{2}$ may have been mediated by the downstream MAPK pathways.

Effects of LOME on LPS-stimulated NF- $\kappa B$ transcriptional activity through the suppression and nuclear translocation of the p65 subunit in RAW264.7 cells. NF- $\mathrm{kB}$ plays a pivotal role in regulating the expression of iNOS, COX-2 and inflammatory cytokines such as TNF- $\alpha$, IL-1 $\beta$ and IL-6 (18). As a plausible molecular mechanism for the inhibition of the inflammatory response, the effect of LOME on the NF- $\mathrm{KB}$ signaling pathway was explored (Fig. 6A). LPS exposure
$(0.5 \mu \mathrm{g} / \mathrm{ml})$ for $30 \mathrm{~min}$ facilitated the degradation of I $\mathrm{BB}-\alpha$, the phosphorylation of IкB- $\alpha$, and the nuclear accumulation of NF- $\kappa B$. However, pre-treatment with LOME inhibited the degradation of I $\mathrm{KB}-\alpha$. Furthermore, LOME decreased the LPS-mediated phosphorylation of I $\mathrm{KB}-\alpha$ and nuclear NF- $\kappa \mathrm{B}$ accumulation in a dose-dependent manner. We further investigated the effect of the LOME on NF-kB activation using immunocytochemistry. The LPS-stimulated translocation of the NF- $\mathrm{KB}$ p65 subunit from the cytosol to the nucleus in the RAW264.7 cells (Fig. 6B), was inhibited by LOME. Thus, the anti-inflammatory effect of LOME may be due to inhibition of the NF- $\mathrm{KB}$ signaling pathway.

LOME and an inhibitor of I $\kappa B-\alpha$ phosphorylation (Bay 11-7082) inhibit NO expression and the activation of $N F-\kappa B$ in LPS-stimulated RAW264.7 cells. In the present study, Bay 11-7082 was used to inhibit the NF- $\kappa B$ pathway. Bay 11-7082, also known as (E)-3-(4-methylphenylsulfonyl)2-propenenenitrile, has a molecular weight of $207.25 \mathrm{kDa}$ and was provided at $\geq 98 \%$ purity (HPLC). It is an irreversible inhibitor of IкB- $\alpha$ phosphorylation, which increases the stabi-

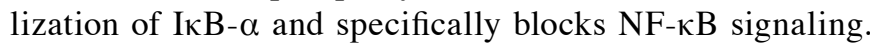
Bay 11-7082 has been shown to be a potent inducer of apoptosis in a number of cancer cell lines. Although Bay 11-7082 has not undergone clinical development, prior in vivo animal experiments have demonstrated its limited toxicity and therapeutic effectiveness $(19,20)$.

LOME significantly suppressed the LPS-induced activation of NF- $\mathrm{KB}$ in the RAW264.7 cells, as shown by western blot analysis. Bay 11-7082 (Calbiochem-Merck, Darmstadt, Germany), a potential anti-inflammatory agent, is an irreversible inhibitor of cytokine-inducible IkB- $\alpha$ phosphorylation $\left(\mathrm{IC}_{50}=10 \mu \mathrm{M}\right)(21)$. Bay 11-7082 blocked the LPS-induced increases in the activation of NF- $\mathrm{KB}$. As expected, LOME $(20 \mu \mathrm{g} / \mathrm{ml})$ inhibited the LPS-induced activation of NF- $\kappa B$ (Fig. 7A). These results suggest that LOME reduces inflammation by inhibiting the LPS-induced activation of NF- $\mathrm{kB}$ in the RAW264.7 cells. In addition, LOME and Bay 11-7082 also affected NO expression. The inhibition of NO expression by each of the compounds was clearly effective (Fig. 7B).

\section{Discussion}

Inflammation not only participates in host defense but also controls the pathogenesis of numerous diseases, including type II diabetes mellitus (22), atherosclerosis (23), obesity (24), silicosis, Alzheimer's disease (25), gout (26) and kidney disease (27). An elevated level of circulating inflammatory cytokines, in particular, and a combined elevation of IL-1 and IL-6, constitute risk factors for the pathogenesis of type II diabetes mellitus. Thus, the reduction of inflammation may be an important therapeutic target for controlling various diseases. In the present study, LOME significantly inhibited the production of $\mathrm{NO}, \mathrm{PGE}_{2}, \mathrm{IL}-6$, IL-1 $\beta$ and TNF- $\alpha$ in the LPS-stimulated RAW264.7 cells, and suppressed the mRNA or protein expression of iNOS, COX-2, and MAPKs (p38 MAPK, JNK and ERK). These results were accompanied by a reduction in the translocation of NF- $\mathrm{kB}$ to the nucleus in the LPS-stimulated RAW264.7 cells.

Among the many pro-inflammatory mediators, $\mathrm{NO}$ and $\mathrm{PGE}_{2}$ play key roles in inflammatory reactions $(28,29)$. $\mathrm{NO}$ is 
A

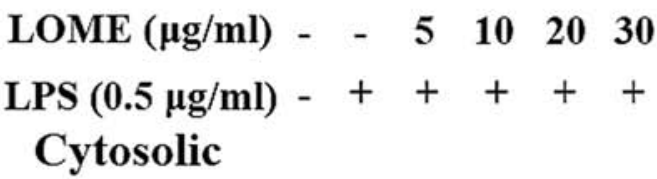

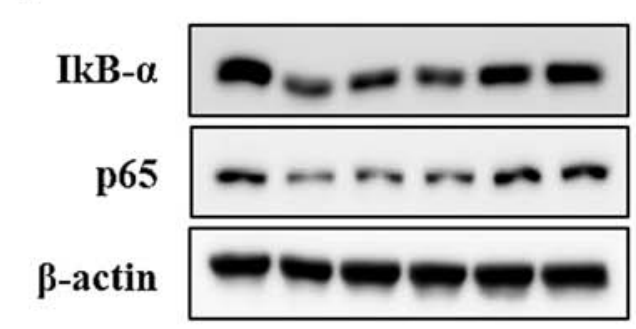

Nuclear

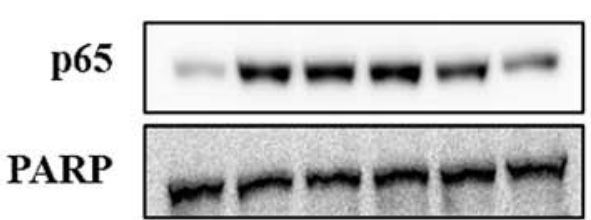

B

$-$

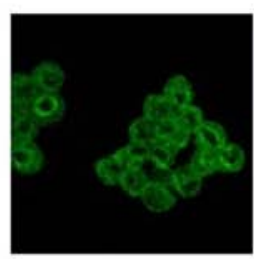

LPS
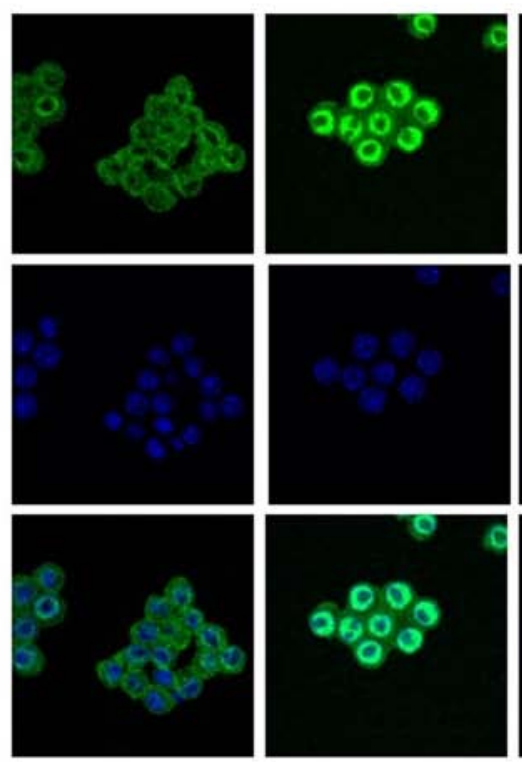

LOME
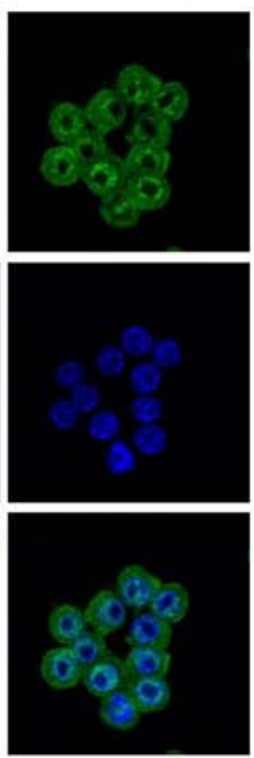

Figure 6. Inhibitory effects of methanolic extract of L. ovalifolia (LOME) on the nuclear translocation of nuclear factor (NF)- $\kappa$ B. (A) The cells were treated with LOME for $1 \mathrm{~h}$, followed by stimulation with lipopolysaccharide (LPS) for $30 \mathrm{~min}$. Equal amounts of protein were analyzed using specific antibodies for I $\kappa$ B- $\alpha$ and p65. The values are expressed as the means \pm SEM of three independent experiments, each performed in triplicate. (B) Immunofluorescent staining of NF- $\kappa \mathrm{B}$ with an NF- $\kappa \mathrm{B}$ antibody and anti-rabbit IgG tagged with Alexa Fluor 488 after fixation (green). The nuclei of the corresponding cells were visualized using DAPI (blue) staining (magnification, x400). Control, DMSO (0.1\%); LPS, LPS only (0.5 $\mu \mathrm{g} / \mathrm{ml})$; LOME, LOME (30 $\mu \mathrm{g} / \mathrm{ml})$ and LPS treatment.

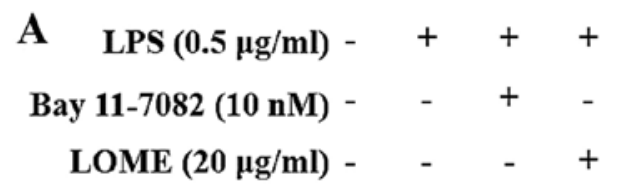

Cytosolic

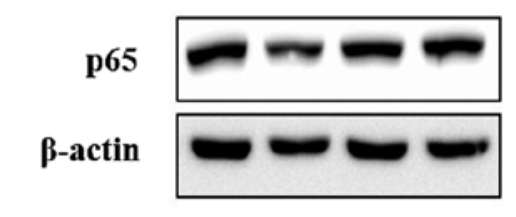

Nuclear

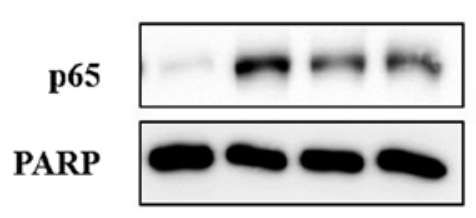

B

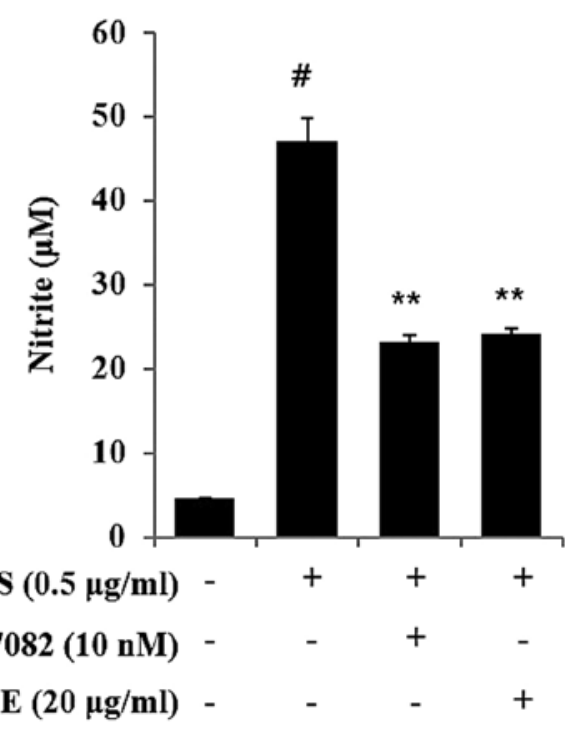

Figure 7. Inhibitory effects of methanolic extract of L. ovalifolia (LOME) and Bay 11-7082 on the nuclear translocation of nuclear factor (NF)-kB and the inhibition of nitric oxide (NO) expression. (A) RAW264.7 cells were treated with increasing concentrations of LOME (30 $\mu \mathrm{g} / \mathrm{ml})$ and Bay 11-7082 for $1 \mathrm{~h}$ and then stimulated with lipopolysaccharide (LPS) $(0.5 \mu \mathrm{g} / \mathrm{ml})$ for $30 \mathrm{~min}$. The nuclear extracts were prepared for western blot analysis of NF- $\mathrm{BB}$ p65 in the nuclear fractions, as described in the Materials and methods. PARP was used as an internal control. (B) RAW264.7 cells were treated with LOME (20 $\mu \mathrm{g} / \mathrm{ml})$ and Bay 11-7082 for $1 \mathrm{~h}$, and then stimulated with LPS $(0.5 \mu \mathrm{g} / \mathrm{ml})$. The NO concentrations were measured using the Griess reaction. Three independent experiments were performed, and the data are presented as the means \pm SEM. ${ }^{*} \mathrm{P}<0.05$ and ${ }^{* *} \mathrm{P}<0.01$, compared with the cells treated with LPS alone. The hash symbol (\#) indicates a significant difference compared to the control group.

generated in different types of cell by at least three isoforms of NOS, among which iNOS is an inducible and $\mathrm{Ca}^{2+}$-independent isoform of NOS. Massive amounts of NO produced by iNOS under inflammatory conditions, are potentially harmful as NO is capable of activating pro-inflammatory signaling to produce oxidative stress. Thus, the inhibition of NO production in response to inflammatory stimuli may be a useful therapeutic strategy in treating inflammatory diseases (30). In addition, prostanoids are a group of lipid mediators that regulate numerous processes in the body. These processes include the regulation of blood pressure, blood clotting, sleep, labor and inflammation. $\mathrm{PGH}_{2}$ is the common substrate for a number of different 
synthases that produce the major prostanoids, including $\mathrm{PGD}_{2}$, $\mathrm{PGE}_{2}$, prostacyclin $\left(\mathrm{PGI}_{2}\right)$, and thromboxane $\left(\mathrm{TXA}_{2}\right)$. Among these, $\mathrm{PGE}_{2}$ plays crucial roles in various biological events including neuronal function, female reproduction, vascular hypertension, tumorigenesis, kidney function and inflammation (31). During inflammatory responses, pain is produced through complex interactions between various inflammatory mediators, one of which is $\mathrm{PGE}_{2}$. Fever is a nearly universal sign of inflammation and infectious processes. Taken together, these findings indicate that $\mathrm{NO}$ and $\mathrm{PGE}_{2}$ are involved in the regulation of various processes of acute and chronic inflammation. Thus, in this study, we examined the effects of LOME on the production of $\mathrm{NO}$ and $\mathrm{PGE}_{2}$. In this analysis, we found that LOME inhibited the LPS-induced production of $\mathrm{NO}$ and $\mathrm{PGE}_{2}$ in the RAW264.7 cells. In addition, the mRNA expression of iNOS and COX-2 was inhibited by LOME. These results indicate that LOME exerts anti-inflammatory effects by downregulating the expression of iNOS and COX-2, and suggests that LOME may act as an anti-inflammatory agent.

The MAPKs are a group of signaling molecules that also appear to play critical roles in inflammatory processes (32). Evidence suggests that the activation of MAPKs is important in the regulation of $\mathrm{NO}$ production, through activation of $\mathrm{NF}-\kappa \mathrm{B}$ (33). In agreement with these previous observations, the LPS stimulation of the RAW264.7 cells caused phosphorylation of the ERK, JNK, and p38 kinases, whereas LOME significantly inhibited ERK and p38 phosphorylation in these same cells (Fig. 5). With a reduction in the phosphorylation of MAPKs, LOME suppressed NF- $\kappa \mathrm{B}$ translocation into the nucleus. These findings indicate that the anti-inflammatory effects of LOME may be closely associated with blocking $\mathrm{NF}-\kappa \mathrm{B}$ translocation into the nucleus, caused by a reduction in the phosphorylation of MAPKs.

$\mathrm{NF}-\kappa \mathrm{B}$ is an important factor that regulates the expression of inflammation-associated mediators, including iNOS, COX-2 and TNF- $\alpha$; which contain NF- $\kappa \mathrm{B}$ binding motifs within their promoters. Many anti-inflammatory agents, such as a methanolic extract of Werklea insignis, exhibit their potency by suppressing NF- $\kappa \mathrm{B}$ signaling (34). In particular, natural products targeting the NF- $\kappa \mathrm{B}$ pathway are considered to be effective in treating inflammatory diseases due to the inhibition of one or more activation steps in the signaling pathway. NF- $\kappa \mathrm{B}$ is a redox-sensitive transcription factor that regulates a multitude of inflammatory genes, including cytokines, chemokines, adhesion molecules and acute phase proteins. In the present study, after treatment with LOME, the level of nuclear NF- $\kappa$ B p 65 was reduced while the cytoplasmic fraction accumulated. Although the reduction in iNOS and COX-2 may be the result of $\mathrm{NF}-\kappa \mathrm{B}$ inactivation, other mechanisms responsible for the effects of LOME effects may not be excluded due to the wide contribution of NF- $\kappa$ B. Thus, LOME may affect the upstream molecular components of $\mathrm{I} \kappa \mathrm{B}-\mathrm{NF}-\kappa \mathrm{B}$ signaling. To clarify the underlying molecular networks, more experiments are warranted. LOME exerts anti-inflammatory effects on RAW264.7 cells and macrophages; however, the detailed molecular mechanisms remain unclear. LOME suppresses LPS-stimulated macrophage inflammatory responses through the blockade of NF- $\kappa \mathrm{B}$; the detailed molecular mechanism involves the inhibition of COX-2 and iNOS expression in RAW264.7 macrophages, through the inactivation of $\mathrm{NF}-\kappa \mathrm{B}$ by blocking the degradation of I $\kappa$ B. These studies, and our data, extend our understanding of the molecular mechanisms underlying the biological activity and pharmacological uses of LOME. In addition, the Bay 11-7082 inhibitor and LOME, attenuated NF- $\kappa$ B activity, thereby inhibiting the expression of NO (Fig. 7B). The ability to inhibit COX-2 and iNOS expression may account, in part, for the anti-inflammatory properties of LOME. Furthermore, to elucidate clearly the mechanism responsible for the antiinflammatory effects of LOME, we examined whether NF- $\mathrm{B}$ was involved in exerting its anti-inflammatory effects using Bay 11-7082 (an NF- $\kappa \mathrm{B}$ inhibitor). Based on these results, we concluded that Bay 11-7082 inhibits NO secretion through its effects on the NF- $\mathrm{B}$ pathway, not by inhibiting the inflammatory response through another mechanism. Taken together, these findings show that LOME has the potential to be used as a potential therapeutic treatment for inflammatory disorders.

In conclusion, this study demonstrated that LOME inhibited the production of $\mathrm{NO}$ and $\mathrm{PGE}_{2}$ as well as pro-inflammatory mediators, in RAW264.7 cells. In addition, LOME reduced the mRNA expression of iNOS and COX-2 by inhibiting the NF- $\mathrm{B}$ and MAPK (ERK, JNK and p38) signaling pathways. These findings suggest that LOME may be used as both a soothing agent and for the treatment of inflammatory diseases.

\section{Acknowledgements}

The present study was supported by grants from the Ministry of Science, ICT and Future Planning (FGC1011534), and from the Korea Research Institute of Bioscience and Biotechnology (KGM1221622) of the Republic of Korea.

\section{References}

1. Lee AK, Sung SH, Kim YC and Kim SG: Inhibition of lipopolysaccharide-inducible nitric oxide synthase, TNF-alpha and COX-2 expression by sauchinone effects on I-kappaBalpha phosphorylation, C/EBP and AP-1 activation. Br J Pharmacol 139: 11-20, 2003.

2. Curran AD: The role of nitric oxide in the development of asthma. Int Arch Allergy Immunol 111: 1-4, 1996.

3. Ketteler M, Cetto C, Kirdorf M, Jeschke GS, Schafer JH and Distler A: Nitric oxide in sepsis-syndrome: Potential treatment of septic shock by nitric oxide synthase antagonists. Kidney Int Suppl 64: S27-S30, 1998.

4. Heo SJ, Yoon WJ, Kim KN, Ahn GN, Kang SM, Kang DH, Affan A, Oh C, Jung WK and Jeon YJ: Evaluation of antiinflammatory effect of fucoxanthin isolated from brown algae in lipopolysaccharide-stimulated RAW 264.7 macrophages. Food Chem Toxicol 48: 2045-2051, 2010.

5. Lu Y, Suh SJ, Kwak CH, Kwon KM, Seo CS, Li Y, Jin Y, Li X, Hwang SL, Kwon O, et al: Saucerneol F, a new lignan, inhibits iNOS expression via MAPKs, NF-kappaB and AP-1 inactivation in LPS-induced RAW264.7 cells. Int Immunopharmacol 12: 175-181, 2012.

6. Mordan LJ, Burnett TS, Zhang LX, Tom J and Cooney RV: Inhibitors of endogenous nitrogen oxide formation block the promotion of neoplastic transformation in $\mathrm{C} 3 \mathrm{H} 10 \mathrm{~T} 1 / 2$ fibroblasts. Carcinogenesis 14: 1555-1559, 1993.

7. Ochoa JB, Udekwu AO, Billiar TR, Curran RD, Cerra FB, Simmons RL and Peitzman AB: Nitrogen oxide levels in patients after trauma and during sepsis. Ann Surg 214: 621-626, 1991

8. Hunt $J$ and Gaston B: Airway nitrogen oxide measurements in asthma and other pediatric respiratory diseases. J Pediatr 137: 14-20, 2000.

9. Giuliano $\mathrm{F}$ and Warner TD: Origins of prostaglandin $\mathrm{E}_{2}$ : involvements of cyclooxygenase (COX)-1 and COX-2 in human and rat systems. J Pharmacol Exp Ther 303: 1001-1006, 2002.

10. Graham A, Nowicke JW, Skvarla JJ, Graham SA, Patel V and Lee S: Palynology and systematics of the Lythraceae. II. Genera Haitia through Peplis. Am J Bot 74: 829-850, 1987. 
11. de Wilde WJJO and Duyfjes BEE: Lagerstroemia (Lythraceae) in Malesia. Blumea - Biodiversity, Evolution and Biogeography of Plants 59: 113-122, 2014.

12. Priyadi H, Takao G, Rahmawati I, Supriyanto B, Ikbal Nursal W and Rahman I: Five hundred plant species in Gunung Halimun Salak National Park, West Java: a checklist including Sundanese names, distribution and use. Cifor: p18, 2010.

13. Burkill IH: A Dictionary of the Economic Products of the Malay Peninsula. Vol. II. Crown Agents, London, p1300, 1935.

14. Su YW, Chiou WF, Chao SH, Lee MH, Chen CC and Tsai YC: Ligustilide prevents LPS-induced iNOS expression in RAW 264.7 macrophages by preventing ROS production and down-regulating the MAPK, NF-kappaB and AP-1 signaling pathways. Int Immunopharmacol 11: 1166-1172, 2011.

15. Park JW, Kwon OK, Kim JH, Oh SR, Kim JH, Paik JH, Marwoto B, Widjhati R, Juniarti F, Irawan D and Ahn KS: Rhododendron album Blume inhibits iNOS and COX-2 expression in LPS-stimulated RAW264.7 cells through the downregulation of NF- $\mathrm{KB}$ signaling. Int J Mol Med 35: 987-994, 2015.

16. Cirino G, Distrutti E and Wallace JL: Nitric oxide and inflammation. Inflamm Allergy Drug Targets 5: 115-119, 2006.

17. Guha M and Mackman N: LPS induction of gene expression in human monocytes. Cell Signal 13: 85-94, 2001.

18. Lawrence T, Willoughby DA and Gilroy DW: Anti-inflammatory lipid mediators and insights into the resolution of inflammation. Nat Rev Immunol 2: 787-795, 2002.

19. Keller SA, Hernandez-Hopkins D, Vider J, Ponomarev V, Hyjek E, Schattner EJ and Cesarman E: NF-kappaB is essential for the progression of KSHV- and EBV-infected lymphomas in vivo. Blood 107: 3295-3302, 2006.

20. Zheng X, Chang RL, Cui XX, Avila G, Huang MT, Liu Y, Kong AN, Rabson AB and Conney AH: Inhibition of NF- $\mathrm{kB}$ by (E)3-[(4-methylphenyl)-sulfonyl]-2-propenenitrile (BAY11-7082; BAY) is associated with enhanced 12-O-tetradecanoylphorbol13-acetate-induced growth suppression and apoptosis in human prostate cancer PC-3 cells. Int J Oncol 32: 257-264, 2008.

21. Mori N, Yamada Y, Ikeda S, Yamasaki Y, Tsukasaki K, Tanaka Y, Tomonaga M, Yamamoto N and Fujii M: Bay 11-7082 inhibits transcription factor NF-kappaB and induces apoptosis of HTLV-I-infected T-cell lines and primary adult T-cell leukemia cells. Blood 100: 1828-1834, 2002.

22. Schroder K, Zhou R and Tschopp J: The NLRP3 inflammasome: a sensor for metabolic danger? Science 327: 296-300, 2010.

23. Duewell P, Kono H, Rayner KJ, Sirois CM, Vladimer G, Bauernfeind FG, Abela GS, Franchi L, Nunez G, Schnurr M, et al: NLRP3 inflammasomes are required for atherogenesis and activated by cholesterol crystals. Nature 464: 1357-1361, 2010.
24. Vandanmagsar B, Youm YH, Ravussin A, Galgani JE, Stadler K, Mynatt RL, Ravussin E, Stephens JM and Dixit VD: The NLRP3 inflammasome instigates obesity-induced inflammation and insulin resistance. Nat Med 17: 179-188, 2011.

25. Halle A, Hornung V, Petzold GC, Stewart CR, Monks BG, Reinheckel T, Fitzgerald KA, Latz E, Moore KJ and Golenbock DT: The NALP3 inflammasome is involved in the innate immune response to amyloid-beta. Nat Immunol 9: $857-865,2008$

26. Martinon F, Petrilli V, Mayor A, Tardivel A and Tschopp J: Goutassociated uric acid crystals activate the NALP3 inflammasome. Nature 440: 237-241, 2006.

27. Tsai PY, Ka SM, Chang JM, Chen HC, Shui HA, Li CY, Hua KF, Chang WL, Huang JJ, Yang SS and Chen A: Epigallocatechin3 -gallate prevents lupus nephritis development in mice via enhancing the Nrf2 antioxidant pathway and inhibiting NLRP3 inflammasome activation. Free Radic Biol Med 51: 744-754, 2011.

28. Goldring MB and Berenbaum F: The regulation of chondrocyte function by proinflammatory mediators: prostaglandins and nitric oxide. Clin Orthop Relat Res 427: S37-S46, 2004

29. Kim HS, Park JW, Kwon OK, Kim JH, Oh SR, Lee HK, Bach TT, Quang BH and Ahn KS: Anti-inflammatory activity of a methanol extract from Ardisia tinctoria on mouse macrophages and paw edema. Mol Med Rep 9: 1388-1394, 2014.

30. Sautebin L: Prostaglandins and nitric oxide as molecular targets for anti-inflammatory therapy. Fitoterapia 71 (Suppl 1): S48-S57, 2000.

31. Kobayashi T and Narumiya S: Prostanoids in health and disease; lessons from receptor-knockout mice. Adv Exp Med Biol 507: 593-597, 2002.

32. Kim JY, Kim HJ, Kim SM, Park KR, Jang HJ, Lee EH, Jung SH and Ahn KS: Methylene chloride fraction of the leaves of Thuja orientalis inhibits in vitro inflammatory biomarkers by blocking NF-kappaB and p38 MAPK signaling and protects mice from lethal endotoxemia. J Ethnopharmacol 133: 687-695, 2011.

33. Ji LL, Gomez-Cabrera MC and Vina J: Role of nuclear factor kappaB and mitogen-activated protein kinase signaling in exercise-induced antioxidant enzyme adaptation. Appl Physiol Nutr Metab 32: 930-935, 2007.

34. Park JW, Kwon OK, Jang HY, Jeong H, Oh SR, Lee HK, Han SB and Ahn KS: A leaf methanolic extract of Wercklea insignis attenuates the lipopolysaccharide-induced inflammatory response by blocking the NF-kappaB signaling pathway in RAW 264.7 macrophages. Inflammation 35: 321-331, 2012. 